Send your letters to the Editor,

British Dental Journal,

64 Wimpole Street

London

W1G 8YS

Email bdj@bda.org

Priority will be given to letters less than 500 words long.

Authors must sign the letter, which

may be edited for reasons of space.

\section{FRAGMENTED PRESENT}

Sir, Dr Ross Hobson in his article A view of European challenges in dental education (BDJ 2009; 206: 65-66) gives an excellent overview of the current position and concerns over dental education in Europe. He also rightly identifies concern that the GDC is failing to lead on UK dental education. The role of the Association of Dental Education in Europe (ADEE) and the Council of European Dentists (CED) is crucial in the 'aim to harmonise the activity of dental schools and to achieve the EU standards of a graduate to be registered within the EU as a dentist'. His article explains how from the mid-1990s ADEE initiated the Dent Ed projects which aimed to use peer review to raise standards. ADEE is an excellent forum for the dental educators to consider and promote policy with the admirable aim to 'promote the advancement of dental education in Europe'.

However, Dr Hobson omits reference to a vital cog in the developmental wheel of EU harmonisation. This vehicle was the Advisory Committee on the Training of Dental Practitioners (ACTDP). Set up in 1978 by directive 78/688/EEC, it consisting of representatives from profession, university and competent authority. The first two categories were easily appointed by each national country, the last was a little more problematic and was interpreted differently in the EU countries - for the UK the GDC is the competent authority and similar regulating bodies existed in other countries. Some did not and a mix of government officials and chief dental officers fulfilled this role. The GDC were strong supporters of the ACTDP with diligent representation by an appointee from the Education
Committee (in my time Professor Robin Basker OBE fulfilled this role). The UK representatives liaised closely with the Department of Health which helped to coordinate policy across the UK health professions and through them EU commission policy in Europe.

The ACTDP successfully worked on the creation of the sectoral directives for dentistry (78/687/EEC and 78/688/ $\mathrm{EEC})$. Implementation of the directives included transitional arrangements as countries entered the EU with very varied existing dental education systems in place. This allowed freedom of movement of dentists throughout Europe. However, in order to achieve convergence in standards of dental education in the EU and place greater emphasis on outcome and comparable competences in primary dental care, ACTDP devised a set of clinical competences (XV/8316/8/93 modified 10/11/98 XV/E/8011/3/97-EN et al.) These were included as an annexe to the 1978 Dental Directive. The work remains a blueprint which subsequently ADEE has further developed.

Regrettably the EU Commission abolished ACTDP in 2000 thereby losing advice that had enhanced the quality and harmonisation of dental education. Fortunately ADEE and CED have filled the void and BDA representation remains strong. But the loss of the former unique tri-partite forum for discussion and implementation has left a more fragmented and less coordinated present. And Dr Hobson's question has to be repeated, why are the GDC not providing a lead in UK (and EU) dental education?

\section{B. Allen $\mathrm{OBE}$}

Essex

DOI: 10.1038/sj.bdj.2009.311

\section{PAEDIATRIC PRACTICES}

Sir, we were concerned to see the description of the cover image of the issue of the journal dated 14 February 2009 since there is no way that the 'Toothbeary' practice is the first paediatric practice in the UK.

The specialist paediatric dental practice that we founded in 1977 predates the Richmond practice by about 32 years. It was designed and built at a time when recognition of the importance of the highest standard of clinical dental care for children was poorly developed in the UK. While we are delighted that other practices should wish to follow our example, we feel that our contribution should not be dismissed.

We feel strongly that at the very least the claim should be retracted and an apology made. We are sure that you would not have wished to cause offence and will seek to remedy the mistake

B. Scheer, J. Roberts, N. Attari

London

Shirin Seehra, Design Director of Dental design and Planning Consultants (DDPC) responds: Thank you for the opportunity to reply to the concerns of your correspondents. DDPC has used the term 'pilot' to indicate that the practice was 'Toothbeary's' first UK practice as a model for future development. The 'Toothbeary' concept originated in Germany - the set up and design of the Richmond practice reflects this concept and is the first of its kind in the UK.

It was not our intention to cause offence to anyone. To avoid any confusion or further offence we will in future describe the practice as 'The UK's first pilot "Toothbeary" practice, based upon the German model, dedicated to providing 
high quality dentistry exclusively for children aged 0-18 years.'

Editor-in-Chief's note: We would like to add our apology for any offence caused as this was, of course, not intended in any way.

DOI: 10.1038/sj.bdj.2009.312

\section{ENJOYABLE ELEVATORS}

Sir, we would like to express our enjoyment of Bussell and Graham's article, The history of commonly used dental elevators (BDJ 2008; 205: 505-508 - see Fig. $1)$ and to elaborate a little on the history of these instruments, before Albucasis. The De Medicina of Aulus Cornelius Celsus (c. $25 \mathrm{BC}-50 \mathrm{AD}$ ) was one of the most widely regarded medical texts of the later Classical world and continued to be considered as essential reading for medical professionals into the Early Modern period (post 1500 AD). Celsus described an operation which would require the use of an elevator: 'But if a

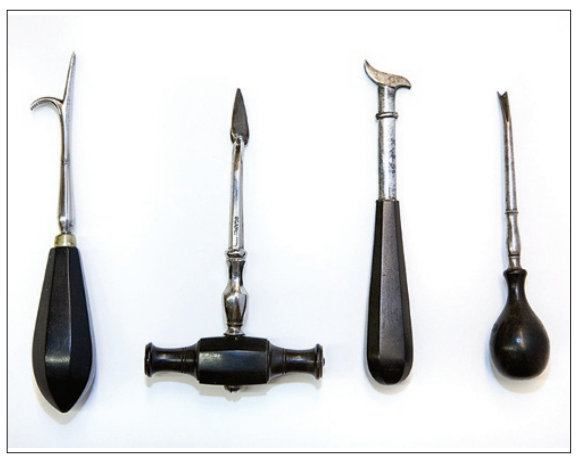

Fig. 1 Examples of early elevators. Reproduction by courtesy of the British Dental Association

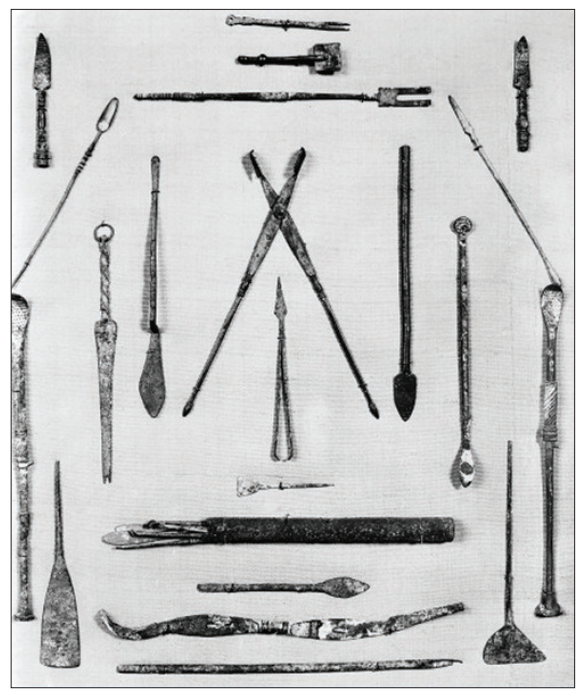

Fig. 2 Roman dental and surgical instruments. Courtesy of the Wellcome Image Archive tooth occasions pain, and it seems proper to extract it, because medicines give no relief, it ought to be scraped all round, that the gum may be loosened from it; then it is to be shook; which must be continued till it move easily'. ${ }^{1}$

We have also identified several instruments dating from the Roman period which may be elevators as they are remarkably similar to those depicted in the illustration from Bussell and Graham's article. We believe that Figure 2 shows an early example of a 'Goat's foot elevator' (middle row, second from left) and 'Spade-shaped' elevators (bottom row second from left).

\section{R. Fitzgerald} Glasgow

D. Sawbridge Edinburgh

- Celsus A C, Grieve J (trans). Aulus Cornelius Celsus: on medicine. In eight books. Translated with notes critical and explanatory. pp 413-414. London, 1756.

DOI: $10.1038 /$ sj.bdj.2009.313

\section{CARE FOR ALL}

Sir, I am writing to request input from my esteemed colleagues. I am in a privileged position to provide domiciliary oral care for the patients that need it. This includes care for patients in residential care homes. I have been doing this for several years now in Newcastle-upon-Tyne.

The patients are in the care homes because they cannot care for themselves and need assistance from carers in every aspect of their lives. However, visiting these care homes I find the oral care for the residents to be very inadequate. Quite often the carers cannot remember when the residents' teeth were last cleaned and look bewildered when their oral care is enquired about. The teeth are caked in plaque of various colour schemes and infused with food. If the resident is a denture wearer, it is a lucky guess if the denture actually belongs to the resident. I have seen many dentures in an unacceptable condition and which certainly have not been cleaned regularly. Carers have a difficult task on their hands and provide excellent care on the whole. Perhaps it is a lack of knowledge about oral care and how to provide it for these patients that leads to this shortcoming.
I have witnessed too many residents in this terrible condition. Surely in our civilised society we can provide our elderly and ability-impaired members with a more complete care?

Perhaps a solution would be regular visits to the care homes by general dental practitioners, community dentists or the oral health promotion team informing carers on oral health care. Another option would be visits by dental students as part of outreach training. This would be mutually beneficial to the care homes and the students.

I would like to ask my esteemed colleagues: is this a universal problem or is this problem isolated to Newcastleupon-Tyne?

A. Korada Newcastle DOI: 10.1038/sj.bdj.2009.314

\section{OWN BRAND PRODUCTS}

Sir, large supermarket chains provide a wide range of popular own brand products for customers who are looking for good value. During this time of recession an increasing number of customers may be financially less well off, and fall within a lower socio-economic group.

Toothpaste is a popular own brand product, and although the own brand toothpaste may be inexpensive, it only contains 1,000 ppm Fl ${ }^{-1}$ (Asda and Tesco) which has been shown to be less effective at preventing caries when compared to $1,450 \mathrm{ppm} \mathrm{Fl}^{-1}$ or more concentrated toothpaste preparations. ${ }^{1}$

There are well documented oral health inequalities in the UK mainly linked to wealth and socioeconomic group. ${ }^{2,3}$

From a dental public health viewpoint, there should be some concern raised about toothpastes being created which are shown to be less clinically effective at preventing oral diseases, but which are specifically targeted at those people who are most at risk from oral disease.

I hope our dental public health colleagues are aware of the situation and are putting some pressure on supermarkets to create more effective 'own brand' health products. I'm sure there would be public outrage and swift intervention from health authorities if supermarkets 
started creating 'own brand condoms' which were 30\% less effective at preventing disease than leading brands.

W. Carter

Teeside

1. British Association for the study of Community Dentistry (BASCD). Delivering better oral health: an evidence based toolkit for prevention. Department of Health, 2007.

2. Watt $\mathrm{R}$, Sheiham A. Inequalities in oral health: review of the evidence and recommendations for action. Br Dent J 1999; 187: 6-12.

3. Jones C M. Capitation registration and socia deprivation in England. An inverse 'dental' care law? Br Dent J 2001; 190: 203-206.

DOI: $10.1038 /$ sj.bdj.2009.315

\section{GUTKA CONSUMPTION}

Sir, with reference to the article on the management of patients with reduced oral aperture and mandibular hypomobility (BDJ 2008; 204: 125-131) and a letter entitled Submucous fibrosis (BDJ 2008; 204: 421) we would like to share with your readers some observations from a country where submucous fibrosis is very common.

Areca nut or betel nut is the seed of the Areca palm called Areca catechu. The fundamental cause of this syndrome is varying degrees of fibrosis in the sub-mucosal layers and in the muscles of mastication leading to a varying degree of trismus. Most authors attribute it to areca nut consumption and partly to smokeless tobacco. ${ }^{1}$ Pan, gutka, pan masala, pan mawa etc are the popular names of tobacco and areca nut combinations in India. ${ }^{2}$ Gutka is the predominant form of areca nut consumption in most parts of India and advertised as a mouth freshener. ${ }^{2-4}$

The various components of this syndrome are:

Chewer's face - typically affecting young or middle-aged persons but also schoolchildren. ${ }^{5}$ It may develop within five years of the habit starting and can include features such as: sunken and stiff cheeks due to loss of facial and buccal fat through chronic malnutrition and fibrosis of the cheek muscles; pseudo-proptosis due to loss of facial, especially peri-ocular fat; pseudo malar prominence due to loss of subcutaneous fat in the peri-orbital area and sunken cheeks.

Chewer's mouth - which shows: pale white oral mucosa, a varying degree of trismus with reduced oral aperture, poor oral hygiene, bald tongue due to loss of papilla, chronic non-healing ulcers in the oral mucosa, extreme sensitivity to heat, cold and spices, retracted soft palate with forward pointing uvula, unhealthy gingivae - chronic gingivitis or gingival recession, unhealthy teeth - teeth are sensitive, abnormally shaped, mal-aligned, premature loss and higher caries incidence, last molar buried in the adjoining buccal mucosa, loss of gingivo-buccal sulcus, loss of tonsillar bulge, reduced salivary outflow due to fibrosis around the Stenson's duct opening.

Chewer's speech - due to progressive fibrosis, the tongue and lip become stiff, resulting in alteration of speech.

Chewer's swallowing - avoidance of eating in public due to reduced mouth opening and consequent inability to eat routine food, altered swallowing due to loss of suppleness of tongue, reduced salivary outflow, dysphagia which although rare causes the oesophagus to show signs of progressive fibrosis and narrowing.

Chewer's hearing impairment due to fibrosis around the eustachian tube opening.

The consumption of gutka or similar products has not only been reported from Asia but also from the Western world. These individuals with submucous fibrosis have a higher incidence of developing oral cancers. ${ }^{4}$

\section{P. Chaturvedi}

Mumbai

1. Tilakaratne W M, Klinikowski M F, Saku T, Peters T J. Warnakulasuriya S. Oral submucous fibrosis: review on aetiology and pathogenesis. Oral Oncol 2006; 42: 561-568.

2. Gupta P C. Mouth cancer in India: a new epidemic? J Indian Med Assoc 1999; 97: 370-373.

3. Gupta P C. Gutka: a major new tobacco hazard in India. Tob Control 1999: 8: 134

4. Boffetta P, Hecht S, Gray N, Gupta P, Straif K Smokeless tobacco and cancer. Lancet Oncol 2008; 9: 667-675.

5. Chaturvedi P. Precancerous lesions in oral cavity of Indian schoolchildren may hint at epidemic. Br Med J 2003; 326: 282

DOI: $10.1038 /$ sj.bdj.2009.316 